\title{
Evolution of pseudohypoparathyroidism: an informative family study
}

\author{
D G D Barr, H F Stirling, J A B Darling
}

Royal Hospital for Sick Children, Edinburgh D G D Barr

Department of Paediatric

Biochemistry

J A B Darling

Department of Child

Life and Health,

University of

Edinburgh

H F Stirling

Correspondence to: Dr D G D Barr, Royal Hospital for Sick Children Sciennes Road, Edinburgh EH9 1LF.

Accepted 5 December 1993

\begin{abstract}
An adult woman with pseudopseudohypoparathyroidism had a child with normal calcium and parathyroid hormone concentrations and cyclic AMP response to injected parathyroid hormone in infancy. By 2.5 years he had features of pseudohypoparathyroidism with raised parathyroid hormone and 'flat' cyclic AMP response. This is the first documented case of a change in parathyroid hormone responsiveness. The abnormal cyclic AMP response to parathyroid hormone in pseudohypoparathyroidism can evolve during childhood.
\end{abstract}

(Arch Dis Child 1994; 70: 337-338)

The classical phenotype in pseudohypoparathyroidism (PHP) and pseudopseudohypoparathyroidism (PPHP) includes short stature, rounded facies, obesity, subcutaneous and basal ganglia calcification, mental retardation, cataracts, and a characteristic brachydactyly that particularly affects the metacarpals, metatarsals, and distal phalanges of the first digits. These features develop gradually during childhood but are highly variable. ${ }^{1}$

The biochemistry of established PHP includes hypocalcaemia, hyperphosphataemia, raised parathyroid hormone concentrations, and unresponsiveness to parathyroid hormone as demonstrated by blunted plasma and urinary cyclic AMP and/or phosphaturic response to injected parathyroid hormone.

The genetics of PHP and PPHP are controversial and have been attributed to both $\mathrm{X}$ linked and autosomal dominant inheritance. Cases of PHP and PPHP can coexist within the same family and may have a common molecular genetic basis.

The mother and son reported here demonstrate that PPHP and PHP are not genetically distinct and that PHP, though inherited, is not necessarily congenital. In this child conversion

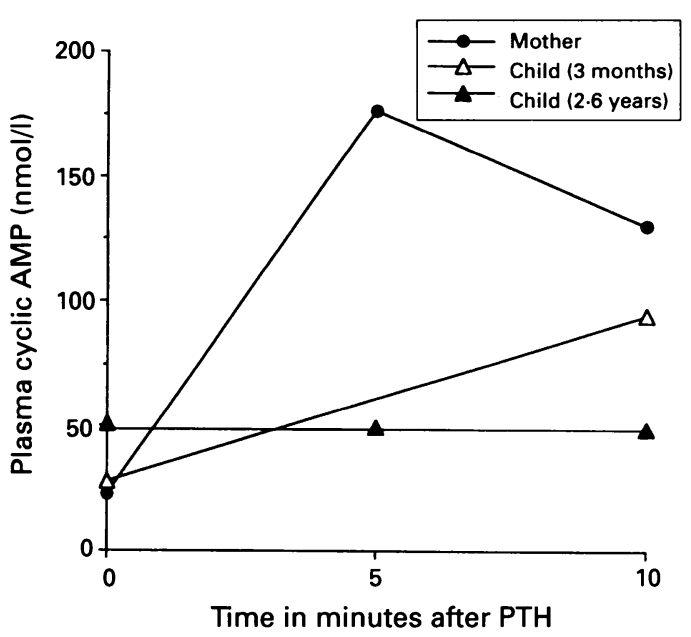

Figure 1 Plasma cyclic AMP responses to injected parathyroid hormone (PTH) in mother and child.

angry outbursts. Biochemical monitoring over a period of 3.5 years has shown serum calcium concentrations in the range 2.12 to $2.29 \mathrm{mmol} / \mathrm{h}$, phosphate in the range 0.70 to $1.36 \mathrm{mmol} / \mathrm{l}$, magnesium $0.64 \mathrm{mmol} / 1$, serum thyroxine $118 \mathrm{nmol} / \mathrm{h}$, thyroid stimulating hormone (TSH) $1.2 \mathrm{mU} / \mathrm{l}$, and free thyroxine $14 \mathrm{pmol} / \mathrm{l}$. Her parathyroid hormone concentration was $<0 \cdot 2 \mathrm{U} / \mathrm{l}$ measured by a C-terminal radioimmunoassay, which was appropriate for her calcium concentration and she had a normal brisk plasma cyclic AMP response to injected parathyroid hormone (fig 1).

Her first child was born at 30 weeks' gestation weighing $1600 \mathrm{~g}$. He was severely asphyxiated and developed respiratory distress syndrome, convulsions, renal failure, and periventricular leukomalacia and died at 3 weeks of age.

Her second child was born at term, and had an uncomplicated neonatal period. She has shown normal psychomotor development, and at 6 years of age is phenotypically normal, growing along the 25 th centile for height with no skeletal abnormalities, and has normal blood biochemistry.

Her third child was born after premature to $\mathrm{PHP}$ unresponsiveness characteristic 3 months and 3 years of age. It is recognised that patients with PHP may change from normocalcaemia to hypocalcaemia. We believe that this is the first documented case of actual change in parathyroid hormone responsiveness from normal to abnormal.

\section{Case reports}

The mother, now aged 24 years, para $3+1$, is of very short stature $(142.2 \mathrm{~cm})$ with short metacarpals and subcutaneous calcification. She is of low normal intelligence, and is prone to mood swings, bouts of depression, and 


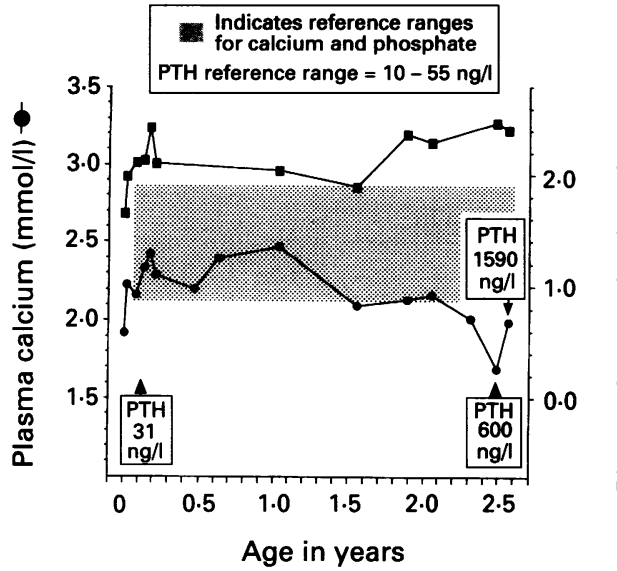

Figure 2 Trends in plasma calcium, phosphate, and serum parathyroid hormone (PTH) during the first three years of the child's life.

concentrations ( $31 \mathrm{ng} / \mathrm{l}$, normal range $10-55$ ). A parathyroid hormone stimulation test was normal for his age, with a significant increase in plasma cyclic AMP from 28 to $94 \mathrm{nmol} / 1$ after injection of parathyroid hormone (fig 1).

By 2.5 years of age he had developed hypothyroidism (TSH $13.4 \mathrm{mU} /$, serum thyroxine $68 \mathrm{nmol} / 1$, free thyroxine $8 \mathrm{pmol} / \mathrm{l}$ ) and was treated with thyroxine. At 2.6 years of age he developed tetany, and was found to be hypocalcaemic with raised serum phosphate and grossly raised parathyroid hormone concentrations (600-1590 ng/l). Repeat parathyroid hormone stimulation test was now abnormal with a flat response (fig 1), that is no increase in cyclic AMP in response to the injected parathyroid hormone. His 25-hydroxyvitamin D concentration was 30 $\mathrm{nmol} / \mathrm{l}$ (normal range $19-55 \mathrm{nmol} / \mathrm{l}$ ) and serum magnesium was $0.98 \mathrm{mmol} / \mathrm{l}$. At the time of his second parathyroid hormone test he had been receiving thyroxine for four weeks and was biochemically and clinically euthyroid (serum thyroxine $161 \mathrm{nmol} / \mathrm{l}$, TSH $0.3 \mathrm{mU} / \mathrm{l}$ ). By this age he also had clinical features of pseudohypoparathyroidism with rounded facies, short stature, subcutaneous calcification, and developmental delay. Griffiths's assessment at 33.5 months chronological age showed locomotor score 21 months, personal social score 22 months, hearing and speech 12.5 months, eye hand coordination 17.5 months, and performance score 17.5 months. $\mathrm{He}$ is currently being treated with thyroxine and alfacalcidol. Serum calcium concentrations have normalised and he has had no further episodes of tetany.

\section{Discussion}

The mother in our family fulfils the criteria for PPHP with no evidence of resistance to parathyroid hormone. Her third child appeared to have inherited the same condition but serial observations demonstrated a transformation to PHP type 1. Mixed kindreds of this type have been described before ${ }^{1}$ and some patients have been observed to fluctuate from hypocalcaemia to normocalcaemia and vice versa. In some this has been reported to be related to vitamin $\mathrm{D}$ status $^{2}$ or chronic hypomagnesaemia. Our child had no clinical, radiological, or biochemical evidence of vitamin $\mathrm{D}$ deficiency with normal 25-hydroxyvitamin $\mathrm{D}$ and magnesium concentrations.

The onset of hypocalcaemia in PHP is highly variable, from the neonatal period onwards. Our child showed an early tendency to hyperphosphataemia but at that time calcium and parathyroid hormone concentrations were normal, and the cyclic AMP response to injected parathyroid hormone was similar to other young infants. ${ }^{3}$ By 2.6 years there was unequivocal evidence of parathyroid hormone resistance, with an absent cyclic AMP response to the injected parathyroid hormone. Such a documented change in cyclic AMP response from normal to abnormal has not been previously described. It is of note that he also developed hypothyroidism at a similar age with a presumed defect in $\mathrm{TSH}$ binding and response.

Increasing parathyroid hormone concentrations may be a protective compensation for impending hypocalcaemia due to a progressive parathyroid hormone receptor defect. Most patients with PHP type 1 have a demonstrable deficiency of the guanine nucleotide binding protein (G protein) which stimulates adenyl cyclase, while others are thought to have a postreceptor defect. Unfortunately serial $G$ protein concentrations are not available in our child, as it would be extremely interesting to correlate any changes in $G$ protein with changes in parathyroid hormone responsiveness.

There is a recognised association with other endocrinopathies including hypothyroidism, gonadotrophin secretory abnormalities, ${ }^{4}$ and growth hormone releasing factor deficiency. The picture is thus one of a heterogeneous set of defects in hormone related cyclic AMP generation. The ontogeny of these systems and the defects that arise therein await further clarification. Molecular genetic studies of the genes encoding for PHP type 1 and the parathyroid hormone receptor are providing information about the basis for the phenotypic variations in this group of conditions. ${ }^{56}$

The two affected members in the family reported here differed in their parathyroid hormone responsiveness. In this child evidence of a transition to parathyroid hormone resistance in terms of the cyclic AMP response to parathyroid hormone has been demonstrated for the first time.

Patients with PPHP are unpredictable in their susceptibility to develop hypocalcaemia and should be kept under long term review.

1 Fitch N. Albright's hereditary osteodystrophy: a review. $A m \mathcal{F}$ Med Genet 1982; 11: 11-29.

2 Drezner MK, Haussler MR. Normocalcaemic pseudohypoparathyroidism: association with normal vitamin D3 metabolism. Am $\mathcal{Y}$ Med 1979; 66: 503-8.

3 Stirling HF, Darling JAB, Barr DGD. Plasma cyclic AMP response to intravenous parathyroid hormone in pseudohypoparathyroidism. Acta Paediatr Scand 1991; 80: 333-8.

4 Levine MA, Downs RW, Moses MA, et al. Resistance to multiple hormones in patients with pseudohypoparathyroidism: association with deficient activity of guanine nucleotide regulatory protein. $A m \mathcal{F} M e d 1983$; 74: 545-56.

5 Patten JL, Johns DR, Valle D, et al. Mutation in the gene encoding the stimulatory G protein of adenylate cyclase in encoding the stimulatory G protein of adenylate cyclase in 322: 1412-9.

6 Schuster V, Eschenhagen T, Kruse K, Gierschik P, Kreth HW. Endocrine and molecular biological studies in a German family with Albright hereditary osteodystrophy. Eur $\mathcal{F}$ Pediatr 1993; 152: 185-9. 